\title{
AN ANALYTICAL STUDY OF GROUNDWATER FLUCTUATIONS IN UNCONFINED LEAKY AQUIFERS INDUCED BY MULTIPLE LOCALIZED RECHARGE AND WITHDRAWAL
}

\author{
R.K. BANSAL ${ }^{1}$ \\ I.S. TELOGLOU ${ }^{2, *}$
}

\author{
${ }^{1}$ Department of Mathematics, National Defence Academy, \\ Khadakwasla, Pune-411023, India \\ ${ }^{2}$ Dept. of Crop Production, School of Agricultural Technology, \\ Alexander Technological Educational Institute of Thessaloniki
}

Sindos-57400, Greece
Received: $13 / 02 / 13$

Accepted: 20/03/13 *to whom all correspondence should be addressed: e-mail: itelo@teithe.gr

\begin{abstract}
Commonly used analytical methods for assessing the effects of recharge and withdrawal on the groundwater flow system are based on an idealistic assumption that the aquifer's base is fully impervious. In reality, the hydrostratigraphic conditions are often complex and involve leakage induced flow between aquifer and the confining layers. In this study, a simple analytical procedure is presented for determining the spatial and temporal distribution of water head in an unconfined aquifer system due to multiple localized recharge and withdrawal at time-varying rates. A new transient function is introduced that can conveniently approximate the rising and recession limbs of any single recharge hydrograph. Solution of linearized two-dimensional groundwater flow equation under Dirichlet and Neumann boundary conditions is obtained using finite Fourier cosine transform with analytic inversion. The study has at least one clear advantage over the existing solutions that it accounts for the vertical leakage in water table buildup and drawdown analysis. A computational example demonstrates that the leakage induced flow plays an important role in recharge and withdrawal processes of unconfined aquifer system. The model results can be used for estimating aquifer's hydraulic properties and validation of numerical models.
\end{abstract}

KEYWORDS: Groundwater; Leakage; Recharge; Drawdown; Wells; Fourier cosine transform.

\section{INTRODUCTION}

The ever increasing demand of water for agriculture, industry and urban use often leads to overexploitation of groundwater resources. Sustainability and the efficiency of an aquifer mainly depend on the applied resource management practices. Special attention should be paid to the rational management of aquifers adjacent to aquatic ecosystems in ecologically sensitive regions where the interaction between surface and groundwater is critical. Furthermore, in coastal areas, excessive pumping of aquifers increases the risk of salinization and deteriorates water supplies both in quantity and quality. A number of pumping or injection wells and recharge basins can be irregularly distributed in space and operated intermittently in an aquifer system. Accurate prediction of water table in an aquifer that is subject to the combined action of pumping and recharge is a prerequisite for proper groundwater management. Therefore, there is a need for developing efficient mathematical model that can describes both spatial and temporal distribution of the groundwater head and the capture zones associated with water sources or withdrawals.

There are numerous mathematical models that have been presented in the literature to predict the groundwater response to the constant or periodically applied recharge in an unconfined aquifer (Hantush, 1967; Marino, 1974b; 1975; Latinopoulos, 1984; Manglik et al. 1997; Rai and Manglik 1999; Teloglou et al., 2008; Bansal and Das, 2011; Manglik et al., 2013). Rastogi and Pandey (1998) used a numerical model to simulate the groundwater head distribution in response to constant 
recharge from recharge basins of different shapes but equal areas. They showed that the groundwater mound underneath a basin was higher when its perimeter decreased.

Several investigators developed models to simulate the groundwater table response to recharge and pumping operations (Manglik et al., 2004; Rai et al., 2006). Chang and Yeh (2007) presented a mathematical model for simulation of groundwater flow in a homogeneous, anisotropic and sloping unconfined aquifer with transient recharge and multiple injection and/or extraction wells. Loáiciga (2008) presented closed-form solutions to the groundwater flow equation in marine island aquifers subject to time-independent and spatially variable dependent recharge and groundwater pumping. Xie et al. (2010) obtained analytical solutions to flow problems with discontinuous boundary conditions due to a circular source (i.e. pumping or recharging well). A comprehensive review of analytical and numerical techniques to solve well-hydraulic problems is presented by Yeh and Chang (2013).

Natural or artificial recharge and pumping rates are some of the most important variables for a regional groundwater model. A corollary of aquifer replenishment is the process of infiltration by which water moves vertically downward into the soil. Infiltration rate generally depends on soil properties such as texture, structure and the existence of layers. Furthermore, the sediment deposition at the bottom of the recharge basins gradually reduces the infiltration rate by clogging the soil pores. In three artificial recharge projects, Mousavi and Rezai (1999) evaluated the improvement of infiltration rate by scraping away various amounts of the upper soil materials. When removing the deposited sediment layer plus $15 \mathrm{~cm}$ of topsoil, maximum restoration degree of the initial infiltration capacity was observed. Mathematically, reduction of the infiltration rate for a single recharge period has been approximated by an exponentially decaying function (Ramana et al., 1995; Rai and Singh, 1996; Teloglou et al., 1997; Chang and Yeh, 2007; Singh and Jaiswal, 2010; Bansal, 2012). For multiple periods of recharge, the infiltration rate has been expressed as a series of line segments (Manglik et al., 1997; Rai et al., 2006; Rai and Manglik, 2012). Teloglou et al. (2008) introduced a generalized polynomial function, approximating the recharge rate during repeated cycles of recharge.

Apart from the recharge and pumping activities, leakage from a semipervious layer at the top or the bottom of an aquifer is a critical issue in analyzing regional groundwater balance. One of the restrictive assumptions in the aforementioned two-dimensional models is that the influence of leakage on the recharge or pumping-induced drawdown is not taken into account by considering an impermeable layer at the bottom of the aquifer. In natural systems, leaky beds occur far more often than perfectly impervious confining beds. Aquifers in deep sedimentary basins are part of multilayered formations whose confining layers are often leaky. When a well in a leaky aquifer is pumped, water is not only withdrawn from the aquifer but also from the underlying aquitard (Malama et al., 2007, Zlotnik and Tartakovsky, 2008). Similarly, when a leaky aquifer is replenished, a significant volume of water flows out through the aquifer-aquitard interface (Teloglou and Bansal, 2012).

In this paper, a new two-dimensional analytical solution is presented for groundwater flow in response to transient recharge and intermittently constant pumping rates from randomly-located basins/wells in an unconfined aquifer resting on a semipervious layer. Transient recharge is approximated by a new exponential function which describes both the rising and the recession limbs of any single recharge hydrograph. By incorporating the leakage term into equation, the upward or downward flow through the semipervious layer is controlled by the local water table height. The linearized form of groundwater flow equation with boundary conditions of prescribed head (Dirichlet) and of zero flux (Neumann) is solved using finite Fourier cosine transform. Omitting certain parameters in the general form of solution leads to more simplified solutions that previously obtained by other researchers. Sensitivity analysis was carried out for various scenarios of recharge and withdrawal operations by changing the hydraulic conductivity of semipervious layer. Numerical results are illustrated in figures and appropriately discussed.

\section{MATHEMATICAL FORMULATION}

As shown in Figure 1, we consider an L-shaped finite aquifer system consisting of an unconfined aquifer underlain by a semipervious bed. The aquifer is in contact with a water body that maintains a constant water head $h_{0}$ along the coastlines $x=A$ and $y=B$. The other two boundaries $x=0$ and $y=$ 0 of the aquifer are impervious, and thus, no flow condition is imposed across these boundaries. It is assumed that the system is in hydraulic equilibrium at the initial stages $(t=0)$ and $h_{0}$ is the initial elevation of the water table. Fluctuations in the phreatic surface are induced by multiple recharge 
and withdrawal activities in the model domain. The recharge basins are rectangular shaped and the dimensions of injection and extraction wells are small compared to the dimension of the aquifer.

The two-dimensional groundwater flow in an unconfined aquifer with semipervious base is governed by the following nonlinear partial differential equation:

$$
\frac{\partial}{\partial x}\left(h \frac{\partial h}{\partial x}\right)+\frac{\partial}{\partial y}\left(h \frac{\partial h}{\partial y}\right)+\frac{1}{K} P(x, y, t)=\frac{S}{K} \frac{\partial h}{\partial t}+\frac{k^{\prime}}{K b^{\prime}}\left(h-h_{0}\right)
$$

where $h(x, y, t)$ is the water table height measured in the vertical direction from the semipervious base; $K$ and $S$ respectively denote the hydraulic conductivity and specific yield of the unconfined aquifer; $k$ and $b$ respectively denote the hydraulic conductivity and thickness of the semipervious bed. The term $P(x, y, t)$ in the left-hand side of the above equation simulates the combined effects of recharge and withdrawal activities in the model domain. These activities are carried out simultaneously using (i) rectangular basins of varying dimensions $a_{i} \times b_{i}$ with arbitrary spatial locations that are responsible for localized transient recharge, and (ii) wells of relatively lesser dimensions that are responsible for injection and/or extraction of the groundwater at time-varying rate. In other words

$$
P(x, y, t)=\left[\sum_{i=1}^{p_{1}} R_{i}(x, y, t)+\sum_{j=1}^{p_{2}} \omega_{j} Q_{j}(t) \delta\left(x-x_{j}\right) \delta\left(y-y_{j}\right)\right]
$$

Here, $p_{1}$ and $p_{2}$ denote the number of rectangular basin and wells respectively. The term $\omega_{j}$ is 1 or 1 according as the $j^{\text {th }}$ well corresponds to an injection or extraction activity. $\delta$ is the Dirac delta function; $Q_{j}(t)$ is the transient rate of injection/extraction in the $j^{\text {th }}$ well $\left(j=1,2, \ldots, p_{2}\right)$ centered at $\left(x_{j}\right.$, $\left.y_{j}\right)$; and $R_{i}(x, y, t)$ is the transient recharge rate in the $i^{\text {th }}$ basin $\left(i=1,2, \ldots, p_{1}\right)$ extending from $x_{i} \leq x \leq$ $x_{i}+a_{i} ; y_{i} \leq y \leq y_{i}+b_{i}$. If $f_{i}(t)$ denotes the rate of recharge in the $i^{\text {th }}$ basin, then

$R_{i}(x, y, t)= \begin{cases}f_{i}(t), & x_{i} \leq x \leq x_{i}+a_{i} ; y_{i} \leq y \leq y_{i}+b_{i} \\ 0, & \text { otherwise }\end{cases}$

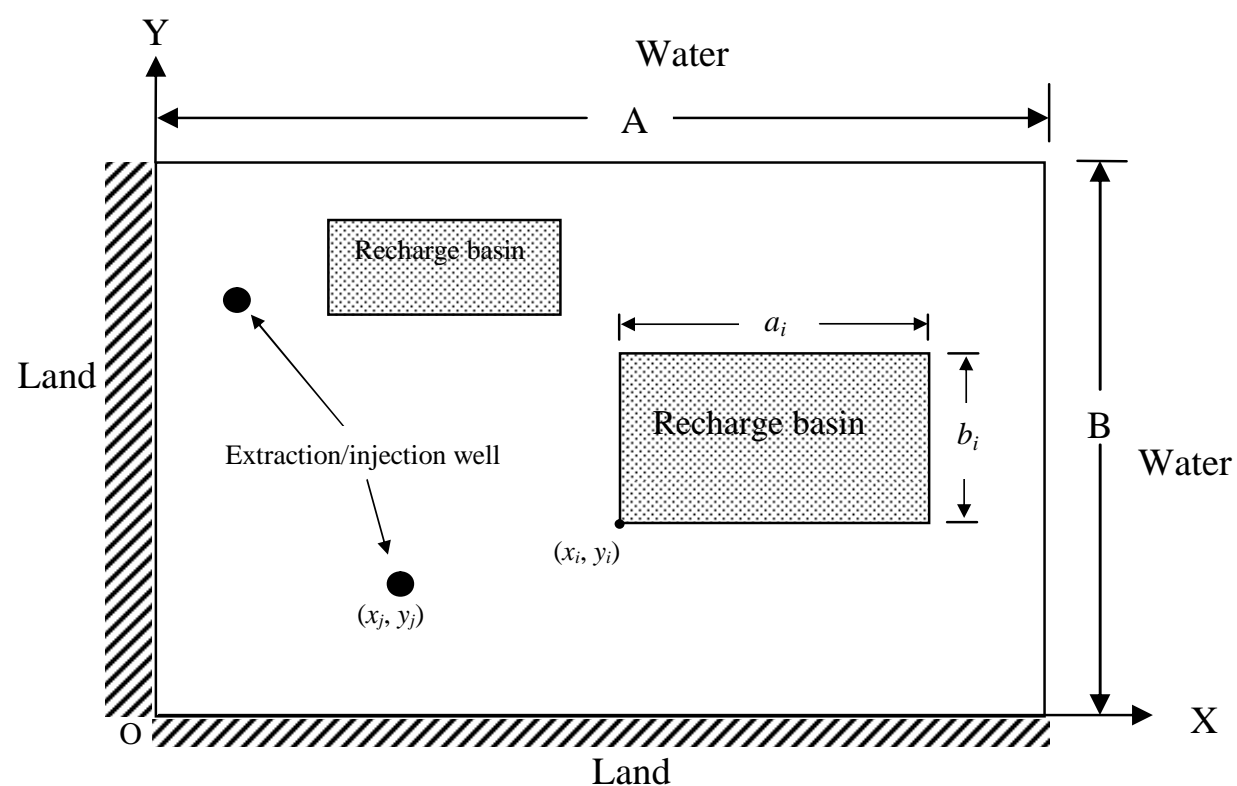

Figure 1. Overview of a leaky unconfined aquifer with multiple recharge basins and extraction wells

The initial and the boundary conditions are prescribed as follows:

$$
\begin{aligned}
& h(x, y, t=0)=h_{0} \\
& \left.\frac{\partial h}{\partial x}\right|_{x=0}=\left.\frac{\partial h}{\partial y}\right|_{y=0}=0 \\
& h(x, y=A, t)=h_{0}=h(x, y=B, t)
\end{aligned}
$$


Equation (1), due to its nonlinearity, does not admit an exact solution. Thus, linearization of this equation is inevitable for obtaining the closed form analytical solution. There are several methods to linearize the groundwater flow equation. Baumann (1952) suggested a linearization method in which the water head $h(x, t)$ is replaced by the sum of characteristic (saturated) depth $D$ and $\xi(x, t)$, where $\xi(x, t)$ is small compared with $D$. Werner (1957) linearized the Boussinesq's equation in terms of $h^{2}$ by replacing the first term on the right-hand side (RHS) of Eq.(1) as $(S / K \bar{h}) \partial\left(h^{2} / 2\right) / \partial t$. The parameters $D$ and $\bar{h}$ that appear in both of the linearization methods denote the mean depth of saturation. Brutsaert (1994) preferred a linearization by which the term $\mathrm{h}$ associated with $\partial \mathrm{h} / \partial x$ is replaced as $p D$, where $p$ is a linearization constant $(0<p \leq 1)$ and $D$ is the saturated thickness of the aquifer.

In this study, we adopt the Werner's method and the value of $\bar{h}$ is obtained by successive use of the formula $\overline{\mathrm{h}}=\left(\mathrm{h}_{0}+h_{t}\right) / 2$, where $\mathrm{h}_{0}$ is the initial water head and $\mathrm{h}_{\mathrm{t}}$ is the water head at the current moment. This approach was suggested by Marino $(1973,1974 \mathrm{a})$ and used in several analytical studies, such as Zissis et al. (2001), Teloglou et al. (2008), Teloglou and Bansal (2012), Bansal (2012) etc. The initial approximation of $\bar{h}$ is taken as $h_{0}$. It must be noted that the analytical solution of the linearized equation offer good approximation of the actual solution if the water table in the aquifer is subjected to small variations.

According to Werner's linearization method, equation (1) is written as

$\frac{\partial^{2} h^{2}}{\partial x^{2}}+\frac{\partial^{2} h^{2}}{\partial y^{2}}+\frac{2}{K} P(x, y, t)=\frac{S}{K \hbar}\left(\frac{\partial h^{2}}{\partial t}\right)+\frac{k^{\prime}}{K b^{\prime} \hbar}\left(h^{2}-h_{0}^{2}\right)$

Setting $H(x, y, t)=h^{2}-h_{0}^{2}$, we get

$\frac{\partial^{2} H}{\partial x^{2}}+\frac{\partial^{2} H}{\partial y^{2}}+\frac{2}{K} P(x, y, t)=\frac{S}{K \hbar} \frac{\partial H}{\partial t}+\frac{k^{\prime}}{K b^{\prime} \hbar} H$

The initial and boundary conditions reduce to

$H(x, y, 0)=0$

$\left.\frac{\partial H}{\partial x}\right|_{x=0}=\left.\frac{\partial H}{\partial y}\right|_{y=0}=0$

$H(x=A, y, t)=0=H(x, y=B, t)$

Equation (6) along with the conditions (7a) - (7c) can be solved using finite Fourier cosine transform. Define (Sneddon, 1974)

$\xi(m, n, t)=F_{c c}\{H(x, y, t) ;(x, y) \rightarrow(m, n)\}=\int_{x=0}^{A} \int_{y=0}^{B} H(x, y, t) \cos \left(\frac{(2 m+1) \pi x}{2 A}\right) \cos \left(\frac{(2 n+1) \pi y}{2 B}\right) d x d y$

The finite Fourier cosine transform reduces the equation (6) to the following form

$-\beta_{m}{ }^{2} \xi-\gamma_{n}{ }^{2} \xi+\frac{2}{K} \bar{P}(m, n, t)=\frac{1}{v} \frac{d \xi}{d t}+c \xi$

where

$$
\begin{aligned}
& \beta_{m}=\frac{(2 m+1) \pi}{2 A} ; \gamma_{n}=\frac{(2 n+1) \pi}{2 B} ; c=\frac{k^{\prime}}{K b^{\prime} \hbar} ; v=\frac{K \hbar}{S} \\
& \bar{P}(m, n, t)=\left[\sum_{i=1}^{p_{1}} \Omega_{i} f_{i}(t)+\sum_{j=1}^{p_{2}} \omega_{j} \eta_{j} Q_{j}(t)\right] \\
& \Omega_{i}=\frac{1}{\beta_{m} \gamma_{n}}\left[\sin \left\{\beta_{m}\left(x_{i}+a_{i}\right)\right\}-\sin \left(\beta_{m} x_{i}\right)\right]\left[\sin \left\{\gamma_{n}\left(y_{i}+b_{i}\right)\right\}-\sin \left(\gamma_{n} y_{i}\right)\right] \\
& \text { and } \quad \eta_{j}=\cos \left(\beta_{m} x_{j}\right) \cos \left(\gamma_{n} y_{j}\right)
\end{aligned}
$$

Rearranging equation (9) as

$$
\frac{d \xi}{d t}+(\alpha+v c) \xi=\frac{2 v}{K} \bar{P}(m, n, t)
$$


where $\alpha=v\left(\beta_{m}^{2}+\gamma_{n}^{2}\right)$

Equation (14) can be solved using ordinary methods. Its solution is

$$
\xi(m, n, t)=\frac{2 v}{K} e^{-(\alpha+v c) t}\left[\sum_{i=1}^{p_{1}} \Omega_{i} \int_{0}^{t} e^{(\alpha+v c) \tau} f_{i}(\tau) d \tau+\sum_{j=1}^{p_{2}} \omega_{j} \eta_{j} \int_{0}^{t} e^{(\alpha+v c) \tau} Q_{j}(\tau) d \tau\right]
$$

where $\mathrm{T}$ is a variable of integration. $H(x, y, t)$ can now be obtained by inverting the finite Fourier transform as

$$
H(x, y, t)=\frac{4}{A B} \sum_{m=0}^{\infty} \sum_{n=0}^{\infty} \xi(m, n, t) \cos \left(\frac{(2 m+1) \pi x}{2 A}\right) \cos \left(\frac{(2 n+1) \pi y}{2 B}\right)
$$

We obtain the solution of equation (5) as

$$
\begin{aligned}
& h^{2}=h_{0}{ }^{2}+\frac{8 v}{A B K} \sum_{m=0}^{\infty} \sum_{n=0}^{\infty} \cos \left(\beta_{m} x\right) \cos \left(\gamma_{n} y\right) e^{-(\alpha+v c) t} \times \\
& {\left[\sum_{i=1}^{p_{1}} \Omega_{i} \int_{0}^{t} e^{(\alpha+\nu c) \tau} f_{i}(\tau) d \tau+\sum_{j=1}^{p_{2}} \omega_{j} \eta_{j} \int_{0}^{t} e^{(\alpha+v c) \tau} Q_{j}(\tau) d \tau\right] }
\end{aligned}
$$

The rate of recharge depends on several hydrologic parameters. For mathematical simplicity, some researchers (Rai and Singh, 1996; Chang and Yeh, 2007 etc.) used an exponentially decaying function of time to approximate the recharge rate. They assumed that

$$
f_{i}(t)=P_{i}+N_{i} e^{-\lambda_{i} t}
$$

where $\lambda_{i}$ is a positive constant, determining the rate at which the recharge in the $I^{\text {th }}$ basin reduces to a final value $P_{i}$ from an initial value $P_{i}+N_{i}$. Similarly, the pumping rate in some studies (Zlotnik 2004; Chang and Yeh 2007 etc.) was considered constant for all values of time, i.e.

$Q_{j}(t)=Q_{j}$

Under such assumption, Equation (18) becomes

$$
\begin{aligned}
h^{2}=h_{0}{ }^{2} & +\frac{8 v}{A B K} \sum_{m=0}^{\infty} \sum_{n=0}^{\infty} \cos \left(\beta_{m} x\right) \cos \left(\gamma_{n} y\right) \times \\
& {\left[\sum_{i=1}^{p_{1}} \Omega_{i}\left\{\frac{P_{i}\left(1-e^{-(\alpha+v c) t}\right)}{\alpha+v c}+\frac{N_{i}\left(e^{-\lambda_{i} t}-e^{-(\alpha+v c) t}\right)}{\alpha+v c-\lambda_{i}}\right\}+\sum_{j=1}^{p_{2}} \omega_{j} \eta_{j} Q_{j}\left(\frac{1-e^{-(\alpha+v c) t}}{\alpha+v c}\right)\right] }
\end{aligned}
$$

If the model domain contains only a single rectangular basin (i.e. $p_{1}=1, p_{2}=0$ ) and the base of the unconfined aquifer is fully impervious $(c=0)$, then equation (21) reduces to the following form:

$$
h^{2}=h_{0}{ }^{2}+\frac{8 v}{A B K} \sum_{m=0}^{\infty} \sum_{n=0}^{\infty} \cos \left(\beta_{m} x\right) \cos \left(\gamma_{n} y\right)\left[\Omega_{1}\left\{\frac{P_{1}\left(1-e^{-\alpha t}\right)}{\beta_{m}{ }^{2}+\gamma_{n}{ }^{2}}+\frac{N_{1}\left(e^{-\lambda_{1} t}-e^{-\alpha t}\right)}{\beta_{m}{ }^{2}+\gamma_{n}{ }^{2}-\lambda_{1}}\right\}\right]
$$

where ${ }_{1}$ can be obtained from equation (12) by setting $i=1$. Equation (22) is same as the equation (15) of Rai and Singh (1996).

In practice, the recharge and withdrawal activities are carried out in discontinuous phases of varying durations (henceforth referred as cycles), each of which is separated by a dry/resting period. In such cases, equation (22) may not satisfactorily approximate the distribution of the water head. Manglik et al. (1997) suggested a method in which a sequence of linear elements of varying slopes and intercepts is used for approximating the recharge and withdrawal rate. They defined

$f_{i}(t)= \begin{cases}r_{i j} t+c_{i j} & t_{j} \leq t \leq t_{j+1} \\ r_{i k} t+c_{i k} & t \geq t_{k}\end{cases}$

where $r_{i j}$ and $c_{i j}$ respectively denote the slope and length of intercept of the $j^{\text {th }}$ element. One perceived drawback of this method is that the approximation of multiple cycles of recharge and withdrawal would need large number of line segments, and thus, the computational cost of the method would be very high. We propose a function that can closely approximate a complete individual cycle of recharge. The function is defined as 


$$
f_{i}(t)=q_{i}\left(t-r_{i}\right) e^{s_{i} t}
$$

where $q_{i}, r_{i}$ and $s_{i}$ are constants. It is shown in Figure 2 that the rising and recession limbs of the recharge of a single hydrograph can be satisfactorily approximated by this function. Here, the solid and dotted lines denote the approximations using equation (24) and (23) respectively. The dry period corresponds to $q_{i}=0$. A sequence of such functions can be used for approximation of the complete recharge operation consisting of multiple cycles of recharge of varying duration. If $\left[t_{i k}, t_{i(k+1)}\right]$ denotes the time interval of $k^{\text {th }}$ recharge cycle of the $i^{\text {th }}$ basin in which the recharge rate is given by

$f_{i k}(t)=q_{i k}\left(t-r_{i k}\right) e^{s_{i k} t}, \quad k=1,2, \ldots$

then we get

$$
\int_{0}^{t} e^{(\alpha+v c) \tau} f_{i}(\tau) d \tau=\sum_{k=1}^{n_{i}-1} D_{i k}+D_{i n_{i}}
$$

where $n_{i}$ is the current cycle in the $i^{\text {th }}$ basin, $t$ is the current time and $t_{i 1}=0$ for all $i$. While the first term in the RHS simulates the effects of first $n_{i}-1$ recharge cycles which are already over; the last term signifies the contribution of the current cycle. The terms $D_{i k}$ and $D_{i n_{i}}$ are given as follows:

$$
\begin{aligned}
D_{i k}=\frac{q_{i k}}{\left(s_{i k}+\alpha+v c\right)}\left[e^{\left(s_{i k}+\alpha+v c\right) t_{i(k+1)}}\left\{\left(t_{i(k+1)}-r_{i k}\right)-\frac{1}{\left(s_{i k}+\alpha+v c\right)}\right\}-\right. \\
\left.e^{\left(s_{i k}+\alpha+v c\right) t_{i k}}\left\{\left(t_{i k}-r_{i k}\right)-\frac{1}{\left(s_{i k}+\alpha+v c\right)}\right\}\right]
\end{aligned}
$$

and

$$
\begin{aligned}
D_{i n_{i}}=\frac{q_{i n_{i}}}{\left(s_{i n_{i}}+\alpha+v c\right)}\left[e^{\left(s_{i n_{i}}+\alpha+v c\right) t}\left\{\left(t-r_{i n_{i}}\right)-\frac{1}{\left(s_{i n_{i}}+\alpha+v c\right)}\right\}\right. \\
\left.-e^{\left(s_{i n_{i}}+\alpha+v c\right) t_{i n_{i}}}\left\{\left(t_{i n_{i}}-r_{i n_{i}}\right)-\frac{1}{\left(s_{i n_{i}}+\alpha+v c\right)}\right\}\right]
\end{aligned}
$$

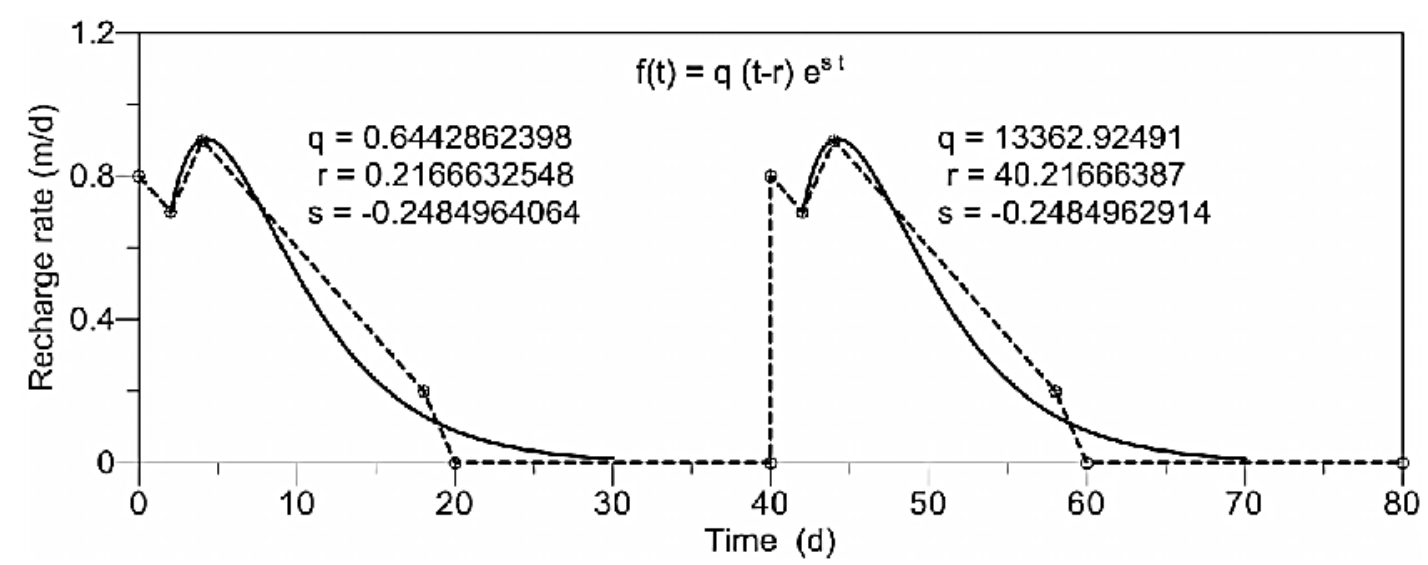

Figure 2. Approximation of rising and recession limbs of recharge hydrograph by linear elements and curve fitting by equation (24)

Similarly, the pumping operation in an injection/extraction well typically consists of discontinuous cycles of varying durations. Without much loss of generality, it can be assumed that the pumping rate throughout a particular cycle remains constant (Figure 3). A dry period corresponds to $Q_{j}=0$. If $\left[t_{j l}, t_{j(l+1)}\right]$ denotes the time interval of $t^{\text {th }}$ pumping cycle in the $f^{\text {th }}$ well in which the pumping rate is given as

$Q_{j l}(t)=Q_{j l}, \quad l=1,2, \ldots$

then 


$$
\int_{0}^{t} e^{(\alpha+\nu c) \tau} Q_{j}(\tau) d \tau=\sum_{l=1}^{m_{j}-1} P_{j l}+P_{j m_{j}}
$$

where $m_{j}$ is the current cycle in the $j^{\text {th }}$ well, $t$ is the current time and $t_{j 1}=0$ for all $j$. The terms $P_{j l}$ and $P_{j m_{j}}$ are given by

$P_{j l}=\frac{Q_{j l}}{(\alpha+v c)}\left[e^{(\alpha+v c) t_{j(l+1)}}-e^{(\alpha+v c) t_{j l}}\right]$

and

$$
P_{j m_{j}}=\frac{Q_{j m_{j}}}{(\alpha+v c)}\left[e^{(\alpha+v c) t}-e^{(\alpha+v c) t_{j m_{j}}}\right]
$$

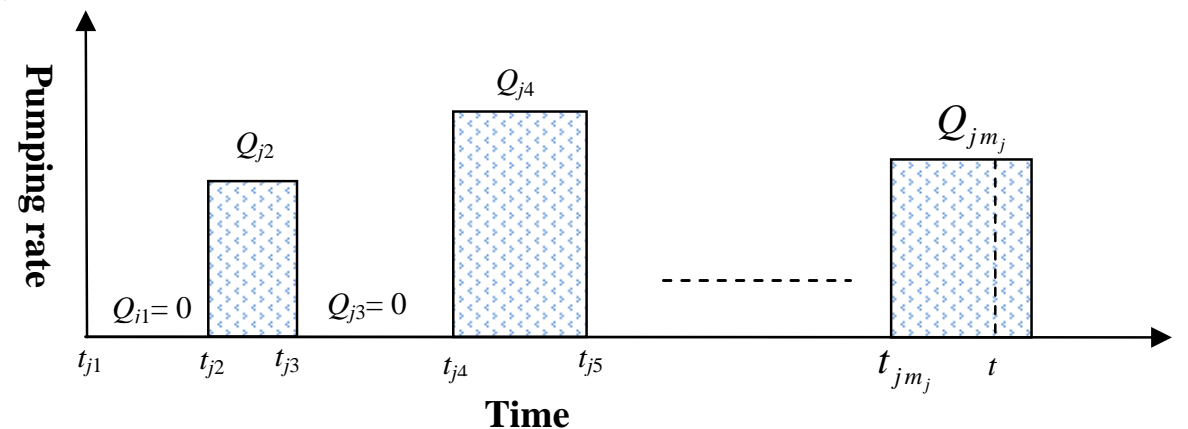

Figure 3. Complete pumping operation in the $j^{\text {th }}$ well consisting of intermittent cycles of constant pumping

The water head distribution in the unconfined aquifer induced by multiple cycles of recharge and withdrawal can now be given as

$$
\begin{aligned}
& h^{2}=h_{0}^{2}+\frac{8 v}{A B K} \sum_{m=0}^{\infty} \sum_{n=0}^{\infty} \cos \left(\beta_{m} x\right) \cos \left(\gamma_{n} y\right) e^{-(\alpha+v c) t} \times \\
& {\left[\sum_{i=1}^{p_{1}} \Omega_{i}\left\{\sum_{k=1}^{n_{i}-1} D_{i k}+D_{i n_{i}}\right\}+\sum_{j=1}^{p_{2}} \omega_{j} \eta_{j}\left\{\sum_{l=1}^{m_{j}-1} P_{j l}+P_{j m_{j}}\right\}\right] }
\end{aligned}
$$

where the terms $D_{i k}\left(k=1,2, \ldots, n_{i}\right)$ and $P_{j l}\left(I=1,2, \ldots, m_{j}\right)$ can be obtained from equations (27) and (30).

\section{DISCUSSION OF RESULTS}

To illustrate the combined effects of time-varying recharge, withdrawal and bed leakage on the water table fluctuations, we consider a leaky aquifer system of dimension $600 \mathrm{~m} \times 400 \mathrm{~m}$. The numerical values of controlling parameters are taken as: $h_{0}=15 \mathrm{~m}, K=10 \mathrm{~m} \mathrm{~d}^{-1}, S=0.25$ and $b=1.5 \mathrm{~m}$. Localized transient recharge is applied through two rectangular basins namely R-1 and R-2 centered at $(150 \mathrm{~m}, 100 \mathrm{~m})$ and $(450 \mathrm{~m}, 300 \mathrm{~m})$ respectively, each of dimension $50 \mathrm{~m} \times 50 \mathrm{~m}$. Moreover, intermittent extraction is considered from two wells $\mathrm{W}-1$ and $\mathrm{W}-2$ located at $(150 \mathrm{~m}, 300 \mathrm{~m})$ and $(450$ $\mathrm{m}, 100 \mathrm{~m}$ ) respectively (Figure 4). 


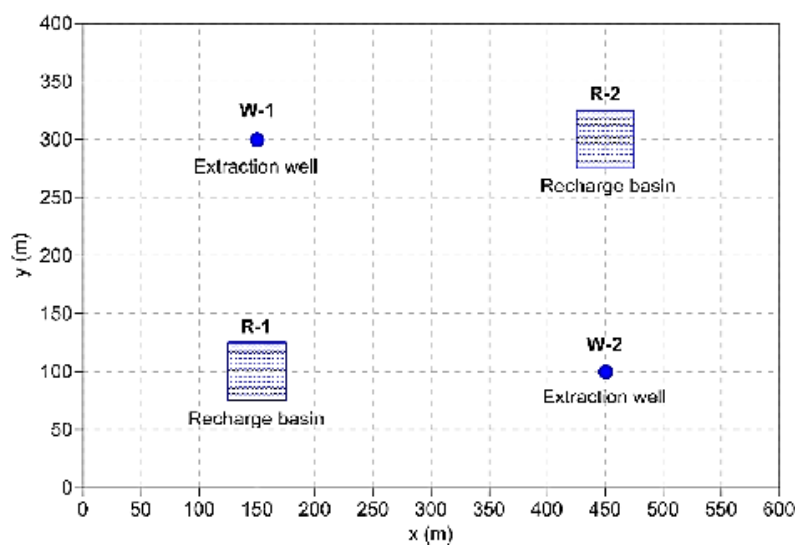

Figure 4. A plan view of aquifer with the relative positions of basins and wells in the numerical example

The dimensions of the extraction wells are small compared to that of the model domain. Recharge and withdrawal activities are taking place simultaneously in the form of disjoint cycles of varying rates and durations, which are separated by a resting period of an arbitrary duration. In the current example, we consider two distinct recharge schemes in basins R-1 and R-2. As shown in Figures 5 and 6, each scheme consists of two disjoint recharge cycles which are preceeded and followed by a dry spell. The rising and recession limbs of the recharge cycles are simulated using the transient function defined by equation (25). Values of parameters $q_{i k}, r_{i k}$ and $s_{i k}(i=1,2$ and $k=1,2,3,4,5)$ used for approximation of the recharge rates are described in Table 1. Extraction activities in wells $\mathrm{W}-1$ and $\mathrm{W}-2$ are carried out in two intermittent cycles. As shown in Figs. 5 and 6, each cycle is preceded and followed by a resting period (i.e. $Q_{i k}=0$ ). Values of pumping rates $Q_{i k}$ for $i=1,2$ and $k$ $=1,2,3,4,5$ are presented in Table 2 .

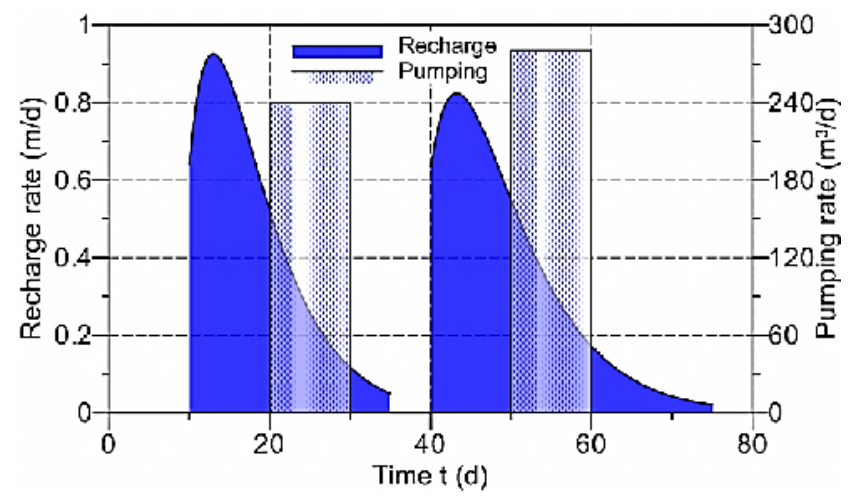

Figure 5. Recharge and pumping scheme in basin R-1 and well W-1

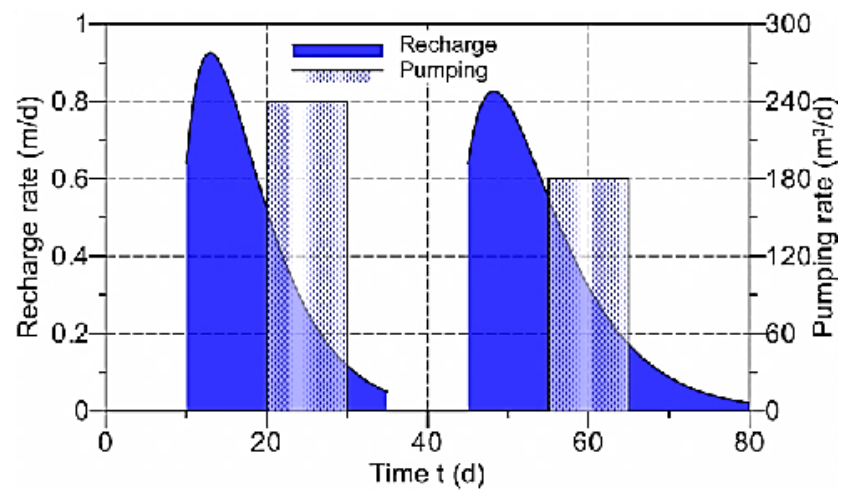

Figure 6. Recharge and pumping scheme in basin R-2 and well W-2 
A FORTRAN programme is written to compute the water head distribution from equation (31). Average saturated depth of the aquifer is calculated using iterative formula $\frac{\bar{h}=\left(\mathbf{h}_{0}+\mathbf{h}_{\mathrm{t}}\right)}{2}$ where $h_{0}$ is the height of initial water table and $h_{t}$ is the height at time $t$, at the end of which $\hbar$ is calculated (Marino, 1973; 1974a; b).

Table 1. Values of parameters $q_{i k}, r_{i k}$ and $s_{i k}$ for recharge schemes in basins R-1 and R-2

\begin{tabular}{ccccccccc}
\hline $\begin{array}{c}\text { Cycle } \\
k\end{array}$ & $t(\mathrm{~d})$ & \multicolumn{3}{c}{ Recharge Basin 1 (R-1) } & \multicolumn{5}{c}{ Recharge Basin 2(R-2) } \\
\hline 1 & $0-9$ & 0 & - & - & $0-9$ & 0 & - & - \\
2 & $10-35$ & 3.02519 & 8.25375 & -0.21092 & $10-35$ & 3.02519 & 8.25375 & -0.21092 \\
3 & $36-39$ & 0 & - & - & $36-44$ & 0 & - & - \\
4 & $40-75$ & 277.378 & 37.4956 & -0.17499 & $45-80$ & 665.36183 & 42.47564 & -0.17499 \\
\hline
\end{tabular}

From computational viewpoint, application of equation 31 is straightforward. The only minor disadvantage is that the sine, cosine and time exponent terms present in the right-hand side of equation (31) produces oscillatory and slow converging values of the double summation. In order to eliminate the oscillations completely and ensure the convergence of the results, one has to take large number of terms $(m=800$ and $n=800)$ and dense grid spacing $(5 \mathrm{~m} \times 5 \mathrm{~m})$. Numerical values of water head heights are obtained for three different values of hydraulic conductivity of the semipervious base, viz. $k=0.25,0.5$ and $0.75 \mathrm{~m} \mathrm{~d}^{-1}$. The corresponding values of hydraulic resistance $b / k$ are 6,3 and $2 \mathrm{~d}$ respectively.

Table 2. Extraction rate $Q_{j k}$ in wells $\mathrm{W}-1$ and $\mathrm{W}-2$

\begin{tabular}{ccccc}
\hline Cycle & \multicolumn{2}{c}{ Extraction Well 1 (W-1) } & \multicolumn{2}{c}{ Extraction Well 2 $(\mathrm{W}-2)$} \\
$k$ & $t(\mathrm{~d})$ & $\mathrm{Q}_{1 k}\left(\mathrm{~m}^{3} \mathrm{~d}^{-1}\right)$ & $t(\mathrm{~d})$ & $\mathrm{Q}_{2 k}\left(\mathrm{~m}^{3} \mathrm{~d}^{-1}\right)$ \\
\hline 1 & $0-19$ & 0 & $0-19$ & 0 \\
2 & $20-30$ & 240 & $20-30$ & 240 \\
3 & $31-49$ & 0 & $31-54$ & 0 \\
4 & $50-60$ & 280 & $55-65$ & 180 \\
5 & $61-75$ & 0 & $66-75$ & 0 \\
\hline
\end{tabular}

Fluctuations in the water table beneath recharge basins are observed after $10 \mathrm{~d}$ when the first cycle of recharge has commenced in both R-1 and R-2. However, significant variations in the water table are observed only after $t=20 \mathrm{~d}$ when the extraction from W-1 and W-2 has started. To outline the combined effects of recharge and withdrawal, the transient profiles of water head along the line $y=$ $300 \mathrm{~m}$ passing through the centers of $\mathrm{W}-1$ and $\mathrm{R}-2$ are plotted at $t=25 \mathrm{~d}$ in Fig. 7(a). At this stage, the pumping rate in $\mathrm{W}-1$ is $240 \mathrm{~m}^{3} \mathrm{~d}^{-1}$ and the recharge rate in R-2 is approximately $0.26 \mathrm{~m} \mathrm{~d}^{-1}$. Fig. 7 (a) demonstrates that evolution of groundwater mound beneath recharge basins largely depends on the hydraulic resistance of the semipervious base. Groundwater mound develops around the vertical line passing through the centre of R-2 whose height increases with the hydraulic resistance. It is observed that the peak values of head gain $h-h_{0}$ at $t=25 \mathrm{~d}$ for $b / \mathrm{k}=2,3$ and $6 \mathrm{~d}$ are respectively $0.337,0.434$ and $0.639 \mathrm{~m}$. Aquifer systems whose base layer is of higher hydraulic resistance are lesser prone to downward leakage, and thus, exhibit higher level of water table in response to recharge. However, the variation might depend on several factors including aquifer parameters and hydraulic properties of the underlying aquitard. Depletion of water table induced by pumping from W-1 is also affected by the bed leakage. For instance, the drawdown $h_{0}-h$ at $t=25 \mathrm{~d}$ for $b / k=2,3$ and $6 \mathrm{~d}$ are $1.2,1.26$ and $1.35 \mathrm{~m}$ respectively. In leaky aquifers, the extraction from wells is partially supported by the aquifer; the balance of groundwater is supplied by leakage induced vertical flow from other hydraulically connected sources. Consequently, the lateral and vertical extent of the cone of depression is mitigated by the bed leakage. These observations 
establish the importance of leakage induced by the recharge and withdrawal mechanisms in an unconfined aquifer system lying on a semipervious base.

Fig. 7(b) presents the profiles of transient water head at $t=60 \mathrm{~d}$ when the second cycle of withdrawal in W-1 and also the second cycle of recharge in R-2 are in progress. Values of other controlling parameters are kept same. At this moment, the pumping rate in $\mathrm{W}-1$ is $280 \mathrm{~m}^{3} \mathrm{~d}^{-1}$ and recharge rate in R-2 is reduced to approximately $0.32 \mathrm{~m} / \mathrm{d}$ from its maximum value of $0.79 \mathrm{~m} \mathrm{~d}^{-1}$. One sees here that the mound height for $b / k=2,3$ and $6 \mathrm{~d}$ are respectively $0.413,0.529$ and $0.77 \mathrm{~m}$ which are comparatively higher than the corresponding values at $t=25 \mathrm{~d}$. To certain extent, the recharge water of the first cycle is responsible for the higher growth; however, the interplay between recharge rate and hydraulic properties of the underlying aquitard cannot be ignored. Groundwater depletion caused by pumping from W-1 is also affected by the first cycle of withdrawal. As a result, the drawdown levels viz. 1.41, 1.47 and $1.59 \mathrm{~m}$ for $b / k=2,3$ and $6 \mathrm{~d}$ are higher in the present case. Also, the lateral extent of depression cone is wider than that of $t=25 \mathrm{~d}$.
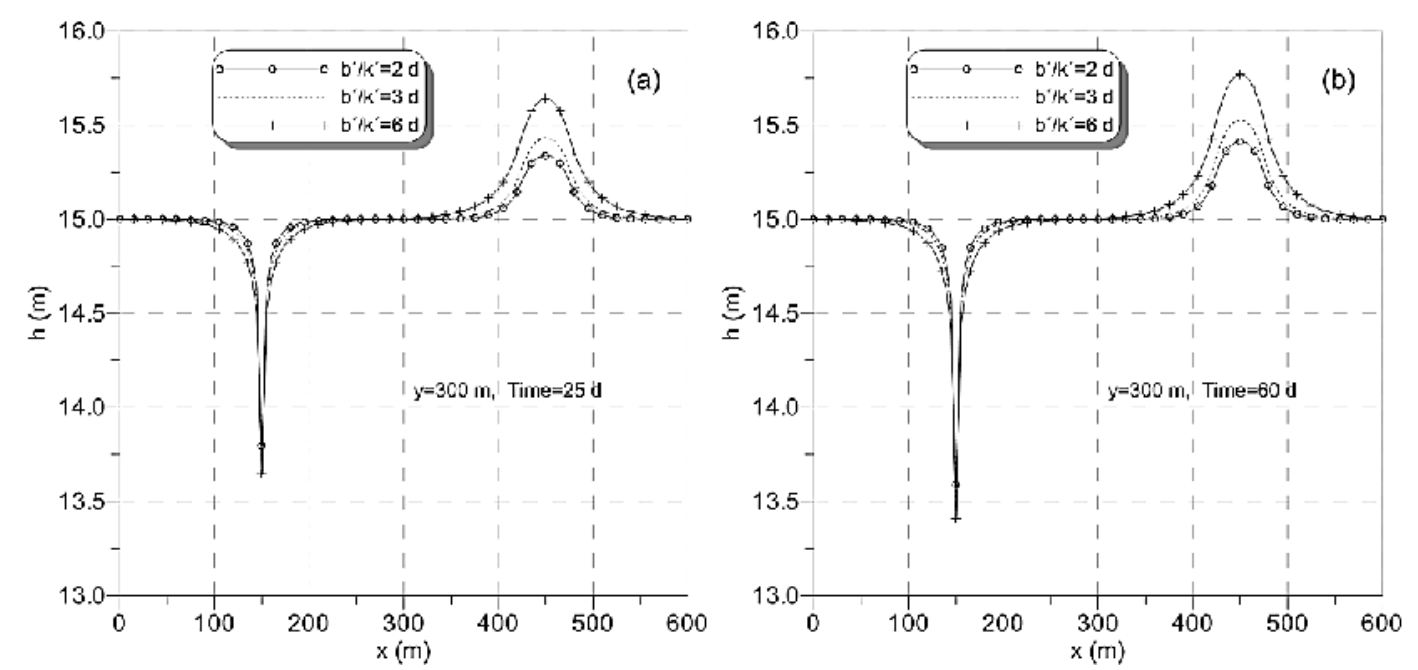

Figure 7. Water head distribution along the line $y=300 \mathrm{~m}$ for $b / k=2,3$ and $6 \mathrm{~d}$ at (a) $25 \mathrm{~d}$, and (b) $60 \mathrm{~d}$

Water table contours and hydraulic gradients diagrams at $t=25$ and $60 \mathrm{~d}$ are plotted in Figures 8 and 9 respectively. The contours are symmetric about the centre lines of recharge basins and extraction wells.
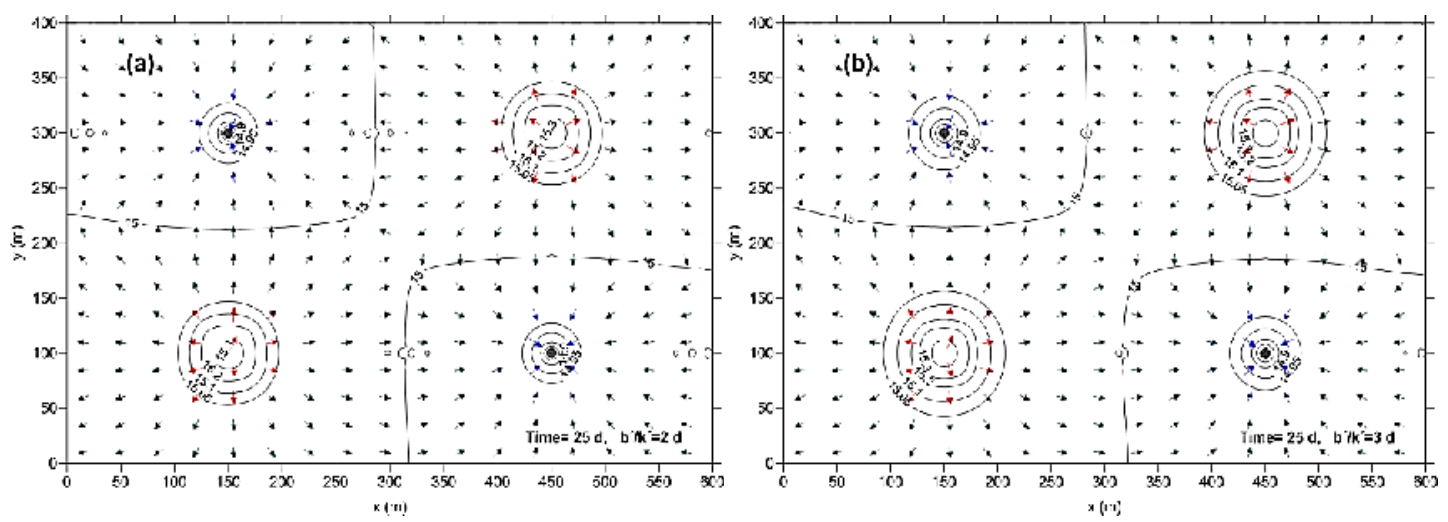


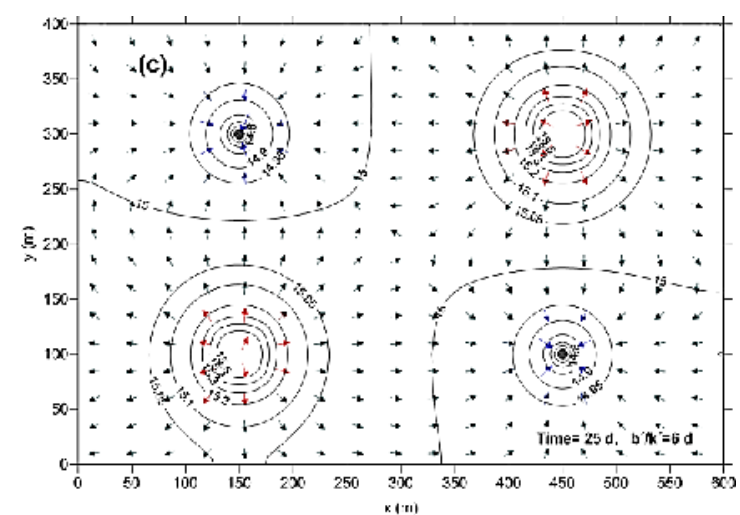

Figure 8. Water table contours and hydraulic gradients in the aquifer at $t=25 d$ for

(a) $b / k=2 d$, (b) $b / k=3 d$ and (c) $b / k=6 d$

Since the first cycle of recharge is identical in both R-1 and R-2; development of water table under these basins is almost similar. However, as indicated by Figures 8(a) - 8(c), the lateral and vertical expansion of groundwater mound is significantly controlled by the hydraulic resistance of semipervious bed. For example, the equipotential $h=15.05$ for $b / k=2 d$ barely reaches to the line $y=50$, whereas it almost approaches to the no-flow boundary $(y=0)$ for higher hydraulic resistance $b / k=6 \mathrm{~d}$. Similarly, the fact that the pumping rate and duration of the first withdrawal cycle in W-1 and W-2 are identical, suggests that the drawdown due to extraction from W-1 and W-2 should follow the same pattern. This behavior can be clearly observed from Figure 8 . As the recharge scenario changes after first cycle, water table under R-1 and R-2 develop differently (Fig. 9). The recharge rate in $\mathrm{R}-2$ during the recession period preceding time $t=60 \mathrm{~d}$ is higher than that of $\mathrm{R}-1$. As a result, the growth of water table beneath $\mathrm{R}-2$ is comparative higher. Similarly, the cones of depression under $\mathrm{W}-1$ and $\mathrm{W}-2$ also differ in vertical and horizontal dimension due to varying rates of withdrawal.

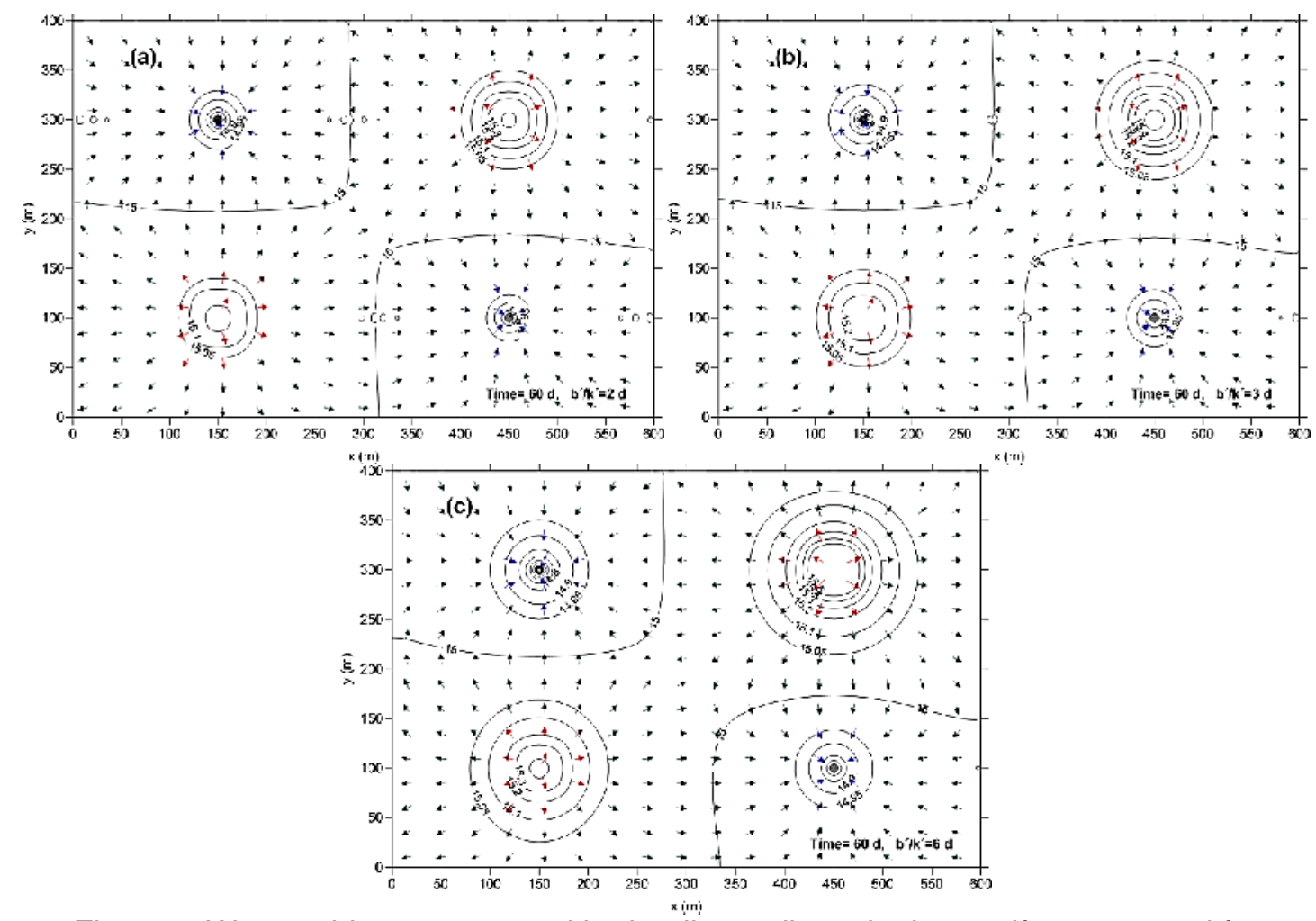

Figure 9. Water table contours and hydraulic gradients in the aquifer at $t=60 \mathrm{~d}$ for

(a) $b / k=2 \mathrm{~d}$, (b) $b / k=3 \mathrm{~d}$ and (c) $b / k=6 \mathrm{~d}$ 


\section{CONCLUSIONS}

Leakage can occur both in confined and unconfined aquifers. Existing solutions developed for assessing water table fluctuations in response to recharge and pumping activities, assume that the base of the aquifer is impervious. This restrictive approach treats the aquifer as an isolated unit in which recharge and withdrawal are assumed to be $100 \%$ linked with the groundwater. Such solutions may not be extendable to the natural systems consisting of leaky aquifers, e.g. multilayered aquifer in deep sedimentary basins where the recharge and withdrawal mechanism of a layer is partially controlled by the hydrological properties of the underlying aquitard.

In this study, we develop an analytical procedure for assessing the effects of recharge and pumping induced leakage flow on the spatio-temporal distribution of water head. The unconfined leaky aquifer is considered to be homogeneous, and the variations in hydraulic conductivity with the spatial variables are neglected. Recharge and withdrawal rates are considered as function of space and time coordinates. Unlike previous studies in which the transient recharge is approximated by an exponentially decreasing function of time or by sequence of several linear elements of varying slopes and intercepts; a new function is proposed that can conveniently approximate the typical rising and recession limbs of any single recharge hydrograph. Closed form expressions are developed that can simulate the combined effects of multiple cycles of recharge, pumping operation and leakage on the water head distribution. In the limiting case, the analytical results reduce to some previously known results. It is demonstrated in the study that the pumping induced drawdown is partially supplied by the underlying aquitard. Similarly, a substantial volume of water flows out through the aquifer-aquitard interface when a leaky aquifer is replenished. As a result, the height of groundwater mound beneath recharge basins increases with the hydraulic resistance $b / k$, and the lateral and vertical extent of the cone of depression due to pumping-induced drawdown is mitigated by the bed leakage. The presented solutions for water head distribution in leaky unconfined aquifers are of practical value from hydrological and geotechnical perspectives. The analytical solution could prove a very useful tool for simulation in the preliminary stage of a groundwater modeling study. Also, this model can be coupled with an optimization procedure for estimating aquifer hydraulic parameters at the regional scale. Apart from practical application, analytical models are useful for testing the accuracy of numerical schemes which are more effective in groundwater management of aquifers with complex hydrogeological settings and irregular boundaries.

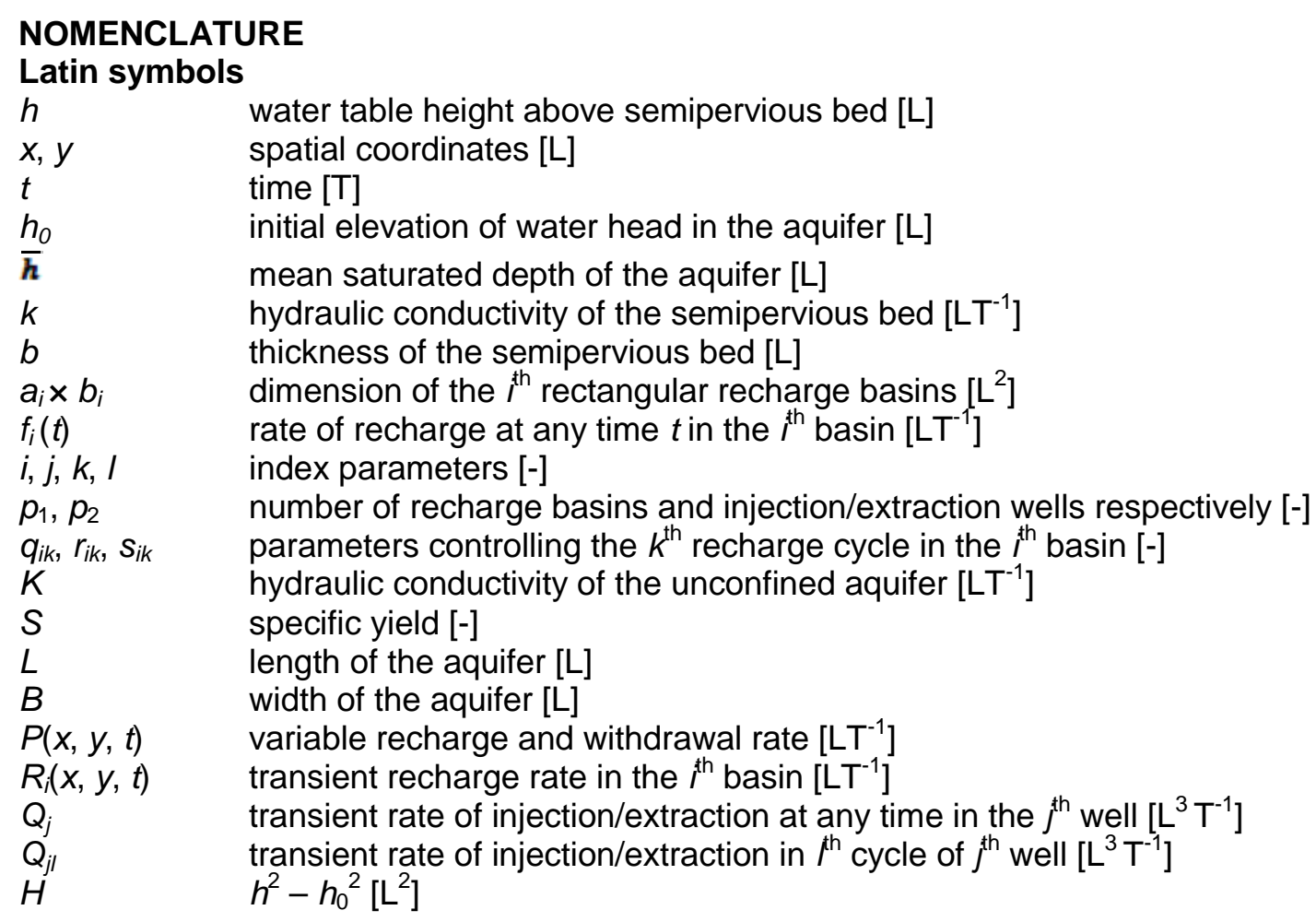




\section{Greek symbols}

$\omega_{j} \quad$ a variable which is 1 for an injection well and -1 for an extraction well [-]

$\delta \quad$ Dirac delta function $\left[\mathrm{L}^{-1}\right]$

\section{REFERENCES}

Bansal R.K. (2012), Groundwater fluctuations in sloping aquifers induced by time-varying replenishment and seepage from a uniformly rising stream, Transport in Porous Media, 94, 817-836.

Bansal R.K. and Das S.K. (2011), Response of an unconfined sloping aquifer to constant recharge and seepage from the stream of varying water level, Water Resources Management, 25, 893-911.

Baumann P. (1952), Groundwater movement controlled through spreading, Trans. Amer. Soc. Civ. Eng., 117, 1024-1074.

Brutsaert W. (1994), The unit response of groundwater outflow from a hilslope, Water Resources Research, 30(10), 2759-2763.

Chang Y.C. and Yeh H.D. (2007), Analytical solution for groundwater flow in an anisotropic sloping aquifer with arbitrarily located multiwells, Journal of Hydrology, 347, 143-152.

Hantush M.S. (1967), Growth and decay of groundwater mounds in response to uniform percolation, Water Resources Research, 3, 227-234.

Latinopoulos P. (1984), Periodic recharge to finite aquifers from rectangular areas. Advance in Water Resources, 7, 137-140.

Loáiciga H.A. (2008), Phreatic surface in island aquifers with regular geometry and time-independent recharge and pumping, Mathematical Geosciences, 40, 199-211.

Malama B., Kuhlman K.L. and Barrash W. (2007), Semi-analytical solution for flow in leaky unconfined aquifer-aquitard systems, Journal of Hydrology, 346, 59-68.

Manglik A., Rai S.N. and Singh R.N. (1997), Response of an unconfined aquifer induced by time varying recharge from a rectangular basin, Water Resources Management,11, 185-196.

Manglik A., Rai S.N. and Singh V.S. (2004), Modelling of aquifer response to time varying recharge and pumping from multiple basins and wells, Journal of Hydrology, 292, 23-29.

Manglik A., Rai S.N. and Singh V.S. (2013), A generalized predictive model of water table fluctuations in anisotropic aquifer due to intermittently applied time-varying recharge from multiple basins, Water Resources Management, 27, 25-36.

Marino M.A. (1973), Water-table fluctuation in semipervious stream-unconfined aquifer systems, Journal of Hydrology, 19, 43-52.

Marino M.A. (1974a), Rise and decline of the water table induced by vertical recharge, Journal of Hydrology, 23, 289-298. Marino M.A. (1974b), Artificial groundwater recharge, I- Circular recharging area, Journal of Hydrology, 25, 201-208.

Marino M.A. (1975), Artificial groundwater recharge, II-Rectangular recharging area, Journal of Hydrology, 26, $29-37$.

Mousavi S.F. and Rezai V. (1999), Evaluation of scraping treatments to restore initial infiltration capacity of three artificial recharge projects in central Iran, Hydrogeology Journal, 7, 490-500.

Rai S.N. and Manglik A. (2012), An analytical solution of Boussinesq equation to predict water table fluctuations due to time varying recharge and withdrawal from multiple basins wells and leakage sites, Water Resources Management, 26, 243-252.

Rai S.N. and Manglik A. (1999), Modelling of water table variation in response to time-varying recharge from multiple basins using the linearized Boussinesq equation, Journal of Hydrology, 220, 141-148.

Rai S. N., Manglik A. and Singh V.S. (2006), Water table fluctuation owing to time varying recharge, pumping and leakage, Journal of Hydrology, 324, 350-358.

Rai S.N. and Singh R.N. (1996), On the prediction of groundwater mound formation due to transient recharge from a rectangular area, Water Resources Management, 10, 189-198.

Ramana D.V., Rai S.N. and Singh R.N. (1995), Water table fluctuation due to transient recharge in a 2-D aquifer system with inclined base. Water Resources Management, 9, 127-138.

Rastogi A. K. and Pandey S. N. (1998), Modeling of artificial recharge basins of different shapes and effect on underlying aquifer system, Journal of Hydrologic Engineering, 3(1), 62-68.

Singh S. and Jaiswal C.S. (2010), Water table fluctuation in the presence of a time-varying exponential recharge and depth-dependent ET in a two-dimensional aquifer system with an inclined base, Journal of Irrigation and Drainage Engineering, 136(7), 502-507.

Sneddon, I.N. (1974), The Use of Integral Transform. Tata McGraw-Hill, New Delhi. 
Teloglou I.S., Zissis T.S. and Karamouzis, N. (1997), Water table fluctuation in soils overlying semiconfined aquifers in response to time-varying replenishment, Journal of Hydrology, 202, 78-94.

Teloglou I.S., Zissis T.S. and Panagopoulos A.C. (2008), Water table fluctuation in aquifers overlying a semi-impervious layer due to transient recharge from a circular basin, Journal of Hydrology, 348, 215-223.

Teloglou I.S. and Bansal R.K. (2012), Transient solution for stream-unconfined aquifer interaction due to time varying stream head and in the presence of leakage, Journal of Hydrology, 428- 429, 68-79.

Xie K., Wang Y., Wang K. and Cai X. (2010), Application of Hankel transforms to boundary value problems of water flow due to a circular source, Applied Mathematics and Computation, 216, 14691477.

Yeh H.D. and Chang Y.C. (2013), Recent advances in modeling of well hydraulics, Advances in Water Resources, 51, 27-51.

Werner P.W. (1957), Some problem in non-artesian groundwater flow, Trans. Am. Geophys. Union., 38(4), 511-518.

Zissis T.S., Teloglou I.S. and Terzidis G.A. (2001), Response of a sloping aquifer to constant replenishment and to stream varying water level, Journal of Hydrology, 243, 180-191.

Zlotnik V.A. (2004), A concept of maximum stream depletion rate for leaky aquifers in alluvial valleys, Water Resources Research, 40(6), W06507. doi:10.1029/2003 WR002932.

Zlotnik V.A. and Tartakovsky D.M. (2008), Stream depletion by groundwater pumping in leaky aquifers. Journal of Hydrologic Engineering, 13(2), 146-155. 